\title{
Defense of taxonomy, a Sisyphus task?
}

\section{Carlos Brisola Marcondes ${ }^{[1]}$}

[1]. Departamento de Microbiologia, Imunologia e Parasitologia, Centro de Ciências Biológicas, Universidade Federal de Santa Catarina, Florianópolis, SC.

\section{Dear Editor,}

Baum et al. ${ }^{1}$ analyzed blood feeding sources (BFSs) of Lutzomyia intermedia in Adrianópolis, located in the northeast region of State of Paraná, by following the description reported by Young \& Duncan ${ }^{2}$. The redescription of Lutzomyia intermedia and the revalidation of Lutzomyia neivai in $1996^{3}$ were corroborated by other authors ${ }^{4}$. Almost all researchers working in the field of entomology have accepted this distinction between the species. After a doctoral thesis on this subject was presented by the present author to the Federal University of Paraná in 1997, another one was presented by José Dilermando Andrade Filho from the Oswaldo Cruz Foundation in 2008.

However, why some researchers are adamant in the nonadoption of this differentiation is difficult to understand; whether this is attributable to the absence of bibliographical research or the disregard of taxonomic precision is not clear. The former pretext is unreasonable, because of the presence of careful bibliographical research and good interpretation of data on the studied insects. The disregard for the differentiation of species that can be easily differentiated, such as Nyssomyia intermedia and Nyssomyia neivai, introduces unnecessary imprecision on the identification of the studied species, devaluing the study and jeopardizing its reference in future studies, an important consequence of the impact of publications. Although one $N y$. intermedia had previously been found in Adrianópolis, besides the 4,649 $N y$. neivai reported previously ${ }^{5}$, this municipality is situated in the Ribeira river Valley where both species have been found in the neighboring region of the State of São Paulo ${ }^{6-9}$. Therefore, the sandflies analyzed were probably all $N y$. neivai, but this cannot be conclusively confirmed. The importance of differentiation is emphasized by the finding of significant differences between the blood-feeding patterns ${ }^{8}$ and seasonal and hourly activity ${ }^{9}$ of $N y$. intermedia and Ny. neivai in the Ribeira Valley at São Paulo. The reference to the observations on the flight range of $N y$. neivai ${ }^{10}$ by Baum et al. ${ }^{1}$ reinforces the disregard on the differentiation of both the species.

The utilization of Nyssomyia as a genus is highly recommendable, unless a disproval is published and generally accepted ${ }^{11}$; however, the correct specific identification of the studied insects is mandatory to prevent the devaluation of published reports.

The usefulness of correct taxonomy has been defended ${ }^{12}$, but this defense seems to be a Sisyphus task, due to the continued

Address to: Dr. Carlos Brisola Marcondes. Dept ${ }^{\circ}$ de Microbiologia, Imunologia e Parasitologia/CCB/UFSC. Campus Trindade, 88040-900 Florianópolis, SC, Brasil.

Phone: 5548 3721-5208; Fax: 5548 3721-3258

e-mail: cbrisolamarcondes@gmail.com

Received 5 December 2013

Accepted 26 January 2014 disregard of some researchers and poor judgment of some journals while accepting manuscripts.

\section{CONFLICT OF INTEREST}

The author declare that there is no conflict of interest.

\section{REFERENCES}

1. Baum M, Ribeiro MCVC, Lorosa ES, Damasio GAC, Castro EA. Eclectic feeding behavior of Lutzomyia (Nyssomyia) intermedia (Diptera: Psychodidae, Phlebotominae) in the transmission area of American cutaneous leishmaniasis, State of Paraná, Brazil. Rev Soc Bras Med Trop $2013 ; 46: 560-565$

2. Young DG, Duncan MA. Guide to the identification and geographic distribution of Lutzomyia sandflies in Mexico, the West Indies; Central and South America (Diptera: Psychodidae). Memoirs of the American Entomology Institute. Vol 54. Gainesville: Associated Publishers -American Entomological Institute; 1994.

3. Marcondes CB. A redescription of Lutzomyia (Nyssomyia) intermedia (Lutz \& Neiva, 1912), and resurrection of L. neivai (Pinto, 1926) (Diptera, Psychodidae, Phlebotominae). Mem Inst Oswaldo Cruz 1996; 91:457-462.

4. Andrade JDA, Galati EAB, Falcão AL. Redescription of Nyssomyia intermedia (Lutz \& Neiva, 1912) and Nyssomyia neivai (Pinto, 1926) Diptera: Psychodidae). Mem Inst Oswaldo Cruz 2004; 98:1059-1065.

5. Santos DR, Santos AR, Poiani LP, De Oliveira O, Da Silva AM, Galati EA. Ocorrência de Nyssomyia intermedia (Lutz \& Neiva) (Diptera: Psychodidae) no Estado do Paraná, Sul do Brasil. Neotrop Entomol 2009; 38:298-301.

6. Marcondes CB, Lozovei AL, Vilela JH. Distribuição geográfica de flebotomíneos do complexo Lutzomyia intermedia (Lutz \& Neiva, 1912) (Diptera, Psychodidae). Rev Soc Bras Med Trop 1998; 31:51-58.

7. Andrade Filho JDA, Galati EAB, Falcão AL. Nyssomyia intermedia (Lutz \& Neiva, 1912) and Nyssomyia neivai (Pinto, 1926) (Diptera: Psychodidae: Phlebotominae) geographical distribution and epidemiological importance. Mem Inst Oswaldo Cruz 2007; 102:481-487.

8. Marassá AM, Galati EAGB, Bergamaschi DP, Gonsals CA. Blood feeding patterns of Nyssomyia intermedia and Nyssomyia neivai (Diptera, Psychodidae) in a cutaneous leishmaniasis endemic area of the Ribeira Valley, State of São Paulo, Brazil. Rev Soc Bras Med Trop 2013; 46:547-554.

9. Galati EAB, Marassá AM, Gonçalves-Andrade RM, Bueno EFM, Paiva BR, Malafronte RS. Nyssomyia intermedia (Lutz \& Neiva) and Nyssomyia neivai (Pinto) (Diptera: Psychodidae: Phlebotominae) in a sympatric area: seasonal and nocturnal hourly rhythm in black and white modified Shannon trap. Rev Bras Ent 2010; 54:677-686.

10. Casanova C, Costa AI, Natal D. Dispersal pattern of the sand fly Lutzomyia neivai (Diptera: Psychodidae) in a cutaneous leishmaniasis endemic rural area in Southeastern Brazil. Mem Inst Oswaldo Cruz 2005; 100:719-724.

11. Marcondes CB. Taxonomic changes: disprove or accept them. Trends Parasitol 2007; 23:302-303.

12. Zavortink TJ. The status of taxonomy of mosquitoes by the use of morphological characters. Mosquito Syst 1974; 6:130-133. 